\title{
Evidence for loss of heterozygosity of $5 q$ in sporadic haemangiomas: are somatic mutations involved in haemangioma formation?
}

J N Berg^, J W Walter^, U Thisanagayam, M Evans, F Blei, M Waner, A G Diamond, D A Marchuk, M E Porteous
Division of Medical and Molecular Genetics, 8th Floor Guy's Tower, Guy's Hospital, London SE1 9RT, UK J N Berg

South-East of Scotland Clinical Genetics Service, Western General Hospital, Edinburgh EH4 2XU, UK

U Thisanagayam M E Porteous

Department of Genetics, Duke University, Durham, North Carolina NC27710, USA

J W Walter

D A Marchuk

Department of Pathology, Sheffield Children's Hospital, Sheffield, UK

$M$ Evans

Department of Otolarygology,

University of Arkansas Medical Centre, Little

Rock, Arkansas

AR72205, USA

$M$ Waner

Departments of Pediatrics and Plastic Surgery, New York University Centre, New York NY10016, USA

F Blei

Department of Microbiology and Immunology, Medical School, University of Newcastle upon Tyne, Newcastle NE2 4HH, UK

A G Diamond

* Should be considered to have contributed equally to this work

Correspondence to: Dr Berg

jonathan.berg@kcl.ac.uk

Accepted for publication 20 September 2000

\begin{abstract}
BackgroundlAims-Haemangiomas are common benign tumours of infancy that consist of rapidly proliferating endothelial cells. A locus for an autosomal dominant predisposition to haemangioma has been identified recently on chromosome 5q. This study aimed to investigate loss of heterozygosity on chromosomes 5 and 9 in haemangiomas.

Methods-Sporadic proliferative phase haemangiomas were microdissected. Polymerase chain reaction amplification and analysis of microsatellite markers on chromosomes 5 and 9 was carried out.

Results-There was a significant loss of heterozygosity for markers on chromosome $5 \mathrm{q}$ in haemangioma tissue, when compared with either markers from chromosome 5p $(p<0.05)$ or markers from chromosome 9 (p< 0.05).

Conclusions-These results suggest that haemangioma formation might be associated with somatic mutational events, and provides evidence that a locus on $5 q$ is involved in the formation of sporadic haemangiomas.

(f Clin Pathol 2001;54:249-252)
\end{abstract}

Keywords: haemangioma; loss of heterozygosity; chromosome 5

Haemangiomas are tumours that consist of proliferating endothelial cells. They affect $1-2 \%$ of neonates, manifesting within the 1 st few weeks of life. ${ }^{1}$ The endothelial cells in the haemangioma, which are rapidly dividing, form microvessels surrounded by pericytes. Lesions pass through phases of rapid proliferation followed by apoptosis and involution. ${ }^{23}$ Immunohistochemical studies suggest that the expression of vascular endothelial growth factor, basic fibroblast growth factor, and type IV collagenase is associated with the endothelial cell proliferation. ${ }^{2}$ Most haemangiomas are sporadic, but haemangiomas can also segregate in families as an autosomal dominant trait, and the locus involved has been identified at 5q31$33 .^{45}$ Most haemangiomas involute without serious sequelae, but a small proportion cause important or life threatening complications. Lesions are usually single, but multiple lesions can occur, usually arising close together.

We hypothesise that the rapid proliferation of endothelial cells in haemangiomas is caused by somatic mutation, which leads to the loss of tumour suppressor gene activity. The same locus might be involved in both sporadic and familial haemangiomas.

The demonstration of loss of heterozygosity (LOH) is commonly used to identify chromosomal regions that have undergone somatic mutation. Semiautomated quantitative detection of $\mathrm{LOH}$ using fluorescently labelled polymerase chain reaction (PCR) products has been described previously. ${ }^{6}$ To our knowledge, no previous study has demonstrated $\mathrm{LOH}$ in sporadic haemangiomas.

In our study, we obtained tissue from sporadic haemangiomas in the proliferative phase. Using microsatellite markers mapping to chromosomes 5 and 9, we looked for $\mathrm{LOH}$ events in microdissected tissue.

\section{Methods}

SAMPLE COLLECTION

Haemangioma tissue was collected from three centres. Tissue from one centre was only available as archived paraffin wax blocks. For these samples, the only clinical details available were diagnosis and histology of haematoxylin and eosin stained sections. Further fresh tissue was obtained from two other surgical centres. For these lesions, the four that amplified successfully were all in the proliferative phase and located on the face (US1: boy with $1.5 \mathrm{~cm}$ lesion beneath nose resected at 9 months of age; US2: girl with $2-3 \mathrm{~cm}$ lesion on forehead resected at 3 months of age; US3: girl with $2 \mathrm{~cm}$ lesion on lower lip resected at 5 months; US4: girl with $1 \mathrm{~cm}$ lesion on right upper eyelid resected at 6 months of age). Individual US4 was reported to have several haemangiomas.

MICRODISSECTION

Formalin fixed, paraffin wax embedded, methyl red stained $10 \mu \mathrm{m}$ thick sections of infantile haemangiomas in the proliferative phase were obtained from three surgical centres. After dewaxing with xylene, sections were overlaid with $200 \mu \mathrm{l}$ of microdissection buffer (20 mM Tris/HCl, $1 \mathrm{mM}$ EDTA, $0.05 \%$ Tween 20, $\mathrm{pH} 8.6)$. Under a dissecting microscope, the region of interest was scraped from the slide using a sterile disposable pipette tip. For each lesion analysed, this procedure was performed twice. To identify the genotype expected in normal tissue from an individual, matched DNA extracted from blood was available for some of the haemangioma samples. Where no peripheral blood DNA was available for analysis, the complete tissue sample from 
Table 1 Loss of heterozygosity (LOH) at chromosome 5 for each marker lesion combination in each of the haemangiomas (denoted UK1, UK2, and US1-4)

\begin{tabular}{|c|c|c|c|c|c|c|c|c|c|c|c|c|c|}
\hline \multirow[b]{2}{*}{ Marker } & \multirow[b]{2}{*}{$\begin{array}{l}\text { Location } \\
\text { (cM) }\end{array}$} & \multicolumn{12}{|c|}{ Haemangioma sample number } \\
\hline & & $\begin{array}{l}\text { UK1 } \\
\text { L1 }\end{array}$ & $L 2$ & $\begin{array}{l}\text { UK2 } \\
L 1\end{array}$ & $L 2$ & \multicolumn{2}{|l|}{ US1 } & US2 & $L 2$ & US3 & $L 2$ & US4 & $L 2$ \\
\hline \multicolumn{14}{|c|}{ Markers from chromosome $5 p$} \\
\hline D5S2849 & 8 & 1.4 & - & $0.50^{\star}$ & $0.25^{\star}$ & - & - & 0.80 & 1.6 & 0.96 & 0.73 & $0.40^{\star}$ & 1.2 \\
\hline D5S2505 & 13 & & & & & 1.2 & 1.6 & - & - & - & - & - & - \\
\hline GATA $134 \mathrm{~B} 03$ & 38 & 1.9 & 1.5 & 1.0 & 1.0 & - & - & - & - & - & - & 1.0 & 0.89 \\
\hline D5S1470 & 49 & - & - & 1.1 & - & - & - & - & - & - & - & - & - \\
\hline \multicolumn{14}{|c|}{ Markers from chromosome $5 q$} \\
\hline D5S 1725 & 98 & 1.1 & 1.1 & 0.69 & 1.5 & - & - & - & - & - & - & - & - \\
\hline D5S1453 & 123 & 0.74 & 0.99 & 1.4 & 1.5 & - & - & - & - & - & - & - & - \\
\hline D5S2501 & 126 & 1.1 & 1.2 & $0.13^{\star}$ & - & $2.0^{\star}$ & $2.2^{\star}$ & - & - & - & $+\inf ^{\star}$ & - & - \\
\hline D5S1505 & 140 & 0.89 & $0.32^{\star}$ & 1.5 & $0.39^{\star}$ & - & - & - & - & - & - & $0.22^{\star}$ & 0.86 \\
\hline D5S816 & 149 & & & & & $2.4^{\star}$ & 1.2 & 0.56 & $0.33^{\star}$ & $2.6^{\star}$ & 0.96 & $+\inf ^{\star}$ & + inf $^{\star}$ \\
\hline D5S1480 & 158 & - & 0.6 & $19^{\star}$ & $4.5^{\star}$ & 1.5 & 1.4 & - & - & - & - & - & - \\
\hline D5S820 & 173 & & & & & - & - & - & - & $3.57^{\star}$ & $2.63^{\star}$ & 0.70 & $2.1^{\star}$ \\
\hline D5S1456 & 192 & _- & _- & & & - & _- & 0.95 & 1.7 & $0.40^{\star}$ & 1.4 & 0.88 & $2.3^{\star}$ \\
\hline
\end{tabular}

The results for each of the two dissections (L1 and L2) are given.

+inf, $\mathrm{LOH}$ was infinite owing to complete loss of one allele; -, the marker was uninformative or marker analysis was attempted but failed.

${ }^{\star} \mathrm{LOH}$ was greater than 2 , denoting significant loss of the larger allele, or less than 0.5 , denoting significant loss of the smaller allele.

The map location of each marker is taken from the Marshfield map set 8 from Research Genetics ${ }^{\mathrm{TM}}$.

Table 2 Loss of heterozygosity at chromosome $9 q(q L O H)$ for each marker lesion combination in haemangiomas US1-4

\begin{tabular}{|c|c|c|c|c|c|c|c|c|c|}
\hline \multirow[b]{2}{*}{ Marker } & \multirow[b]{2}{*}{$\begin{array}{l}\text { Location } \\
(c M)\end{array}$} & \multicolumn{8}{|c|}{ Haemangioma sample number } \\
\hline & & $\begin{array}{l}\text { US1 } \\
\text { L1 }\end{array}$ & $L 2$ & $\begin{array}{l}\text { US2 } \\
\text { L1 }\end{array}$ & $L 2$ & $\begin{array}{l}\text { US3 } \\
\text { L1 }\end{array}$ & $L 2$ & $\begin{array}{l}\text { US4 } \\
\text { L1 }\end{array}$ & $L 2$ \\
\hline GATA62F03 & 0 & 0.54 & 1.3 & 1.1 & - & 1.6 & - & - & $3.83^{\star}$ \\
\hline D9S925 & 11 & 0.91 & 0.56 & 1.3 & - & $2.3^{\star}$ & 1.1 & 0.86 & - \\
\hline D9S922 & 63 & - & 0.69 & 0.66 & - & $3.3^{\star}$ & $2.2^{\star}$ & 0.69 & - \\
\hline D9S910 & 92 & 1.3 & 1.2 & - & - & - & - & - & - \\
\hline D9S934 & 117 & 1.0 & 0.82 & 1.0 & - & 1.2 & - & 0.73 & - \\
\hline D9S158 & 156 & - & - & 1.7 & 1.1 & - & - & - & - \\
\hline
\end{tabular}

The results for each of the two dissections ( $\mathrm{L} 1$ and $\mathrm{L} 2$ ) are given.

+inf, qLOH was infinite owing to complete loss of one allele; -, the marker was uninformative, or marker analysis was attempted but failed.

${ }^{\star} \mathrm{qLOH}$ was greater than 2 , denoting significant loss of the larger allele, or less than 0.5 , denoting significant loss of the smaller allele.

The map location of each marker is taken from the Marshfield map set 8 from Research Genetics ${ }^{\mathrm{TM}}$.

an independent section of the same lesion, comprising skin, fatty tissue and lesion, was removed into buffer as a control reaction to give the expected genotype.

Buffer and tissue were transferred to a microcentrifuge tube and incubated with $20 \mu \mathrm{l}$ of proteinase $\mathrm{K}(20 \mathrm{mg} / \mathrm{ml})$ for 16 hours at $50^{\circ} \mathrm{C}$, followed by heating to $100^{\circ} \mathrm{C}$ for 10 minutes to inactivate the proteinase $\mathrm{K}$. Aliquots $(2 \mu \mathrm{l})$ of this extract were subsequently used for PCR amplification of markers.

MARKER ANALYSIS

Primers used were from Marshfield set 8, obtained from Research Genetics ${ }^{\mathrm{TM}}$. Primer sequences and marker maps are available via the Marshfield Medical Research Foundation web site (www.marshmed.org/genetics/). Primers were FAM, HEX, or TET labelled. PCR amplification from $2 \mu \mathrm{l}$ of DNA solution was performed according to the manufacturer's recommended conditions in 96 well plates. After amplification, products were run on an $\mathrm{ABI} 377^{\mathrm{TM}}$ sequencer and analysed using GeneScan v2.02 $2^{\mathrm{TM}}$ software. Markers clearly showing the presence of two alleles in the control tissue, and with one or two alleles of the correct size in the microdissection tissue sample, were considered "informative" and were analysed further. The ratio of the peak areas of the smaller to larger fragment was calculated for the control sample from the individual, and for each of the two samples from the lesion. These were designated $\mathrm{ql}$ (lesion) or qc (control). Loss of heterozygosity was taken as having occurred if $\mathrm{ql} / \mathrm{qc}$ deviated significantly ( $<0.5$ or $>2.0$ ) from the expected value of $1 .^{67}$

STATISTICAL ANALYSIS

The number of markers showing $\mathrm{LOH}$ on chromosome $5 \mathrm{q}$ was compared with the number of markers showing LOH on chromosomes $5 \mathrm{p}$ and 9 . Statistical analysis involved the construction of a two by two table and the use of the $\chi^{2}$ test with one degree of freedom.

\section{Results}

Six proliferative phase haemangiomas were successfully microdissected and amplified. In total, 86 sample/marker combinations were successfully amplified and were informative. These data are shown in tables 1 and 2 and are summarised in table 3 . The total number of LOH events identified on chromosome $5 \mathrm{q}$ was compared with the number of $\mathrm{LOH}$ events

Table 3 Number of informative marker lesion combinations, and number of loss of heterozygosity (LOH) events seen for each chromosomal location

\begin{tabular}{|c|c|c|c|c|c|c|c|c|}
\hline \multirow{2}{*}{$\begin{array}{l}\text { Chromosomal } \\
\text { location }\end{array}$} & \multicolumn{6}{|c|}{ No. of $\mathrm{LOH}$ events (total number of informative combinations) } & \multirow{2}{*}{$\begin{array}{l}\text { Total no. of informative } \\
\text { marker/lesion combinations }\end{array}$} & \multirow{2}{*}{$\begin{array}{l}\text { Total no. of } \\
\text { informative LOH } \\
\text { events seen }\end{array}$} \\
\hline & UK1 & UK2 & US1 & US2 & US3 & US4 & & \\
\hline 9 & & & $0(9)$ & $0(6)$ & $3(6)$ & $1(4)$ & 25 & 4 \\
\hline $5 p$ & 0 (3) & $2(5)$ & $0(2)$ & $0(2)$ & $0(2)$ & $1(4)$ & 18 & 3 \\
\hline $5 q$ & $1(9)$ & $4(9)$ & $3(6)$ & $1(4)$ & $5(7)$ & $5(8)$ & 43 & $19^{\star}$ \\
\hline Total & & & & & & & 87 & 26 \\
\hline
\end{tabular}

This information is given for each haemangioma successfully analysed, as well as for the total data set.

*A significantly greater $(\mathrm{p}<0.05)$ proportion of $\mathrm{LOH}$ events for markers on chromosome $5 \mathrm{q}$ than for markers on either chromosome 9 or chromosome $5 \mathrm{p}$ (using the $\chi^{2}$ test with 1 degree of freedom). 
identified in control markers from chromosome $5 \mathrm{p}$. In a subset of lesions, markers from chromosome 9 were analysed. This was initially performed because the endoglin gene, responsible for vascular dysplasia hereditary haemorrhagic telangiectasia type 1 (HHT), maps to $9 \mathrm{q} 34$, although we recognise that a different pathological process is involved in lesion formation in HHT.

Using the $\chi^{2}$ test, significantly more markers showed LOH on chromosome $5 \mathrm{q}$ than on chromosome $5 p(p<0.05)$ or chromosome 9 $(\mathrm{p}<0.05)$.

Examining data from individual lesions, three haemangiomas showed $\mathrm{LOH}$ for three or more markers tested on 5q. In these lesions (UK2, US3, and US4), the LOH was distal to D5S1453, although no distal limit to the region of $\mathrm{LOH}$ on $5 \mathrm{q}$ was identified.

\section{Discussion}

We have demonstrated LOH for DNA markers on chromosome $5 \mathrm{q}$ in a proportion of proliferative haemangiomas. This suggests that somatic mutational events on $5 \mathrm{q}$ have a role in haemangioma formation.

Analysis for $\mathrm{LOH}$ is invariably complicated by the contamination of tumour tissue with normal surrounding tissue. The cut off point used for the identification of $\mathrm{LOH}$ assumes that the mutational event is seen in $>50 \%$ of the cellular DNA sampled. The preferential amplification of one (usually the smaller) allele is a recognised complication of PCR amplification from small amounts of DNA. However, in the $19 \mathrm{LOH}$ events seen on $5 \mathrm{q}$, six of 19 events involved loss of the smaller allele. Statistical comparison of the number of $\mathrm{LOH}$ events seen on $5 q$ with those on $5 p$ and chromosome 9 also reduces this as a source of error.

The chromosomal regions showing $\mathrm{LOH}$ on $5 \mathrm{q}$ overlap with the candidate interval demonstrated for hereditary haemangioma by Walter et $a l,{ }^{5}$ even though we recognise that the candidate interval published is very large, and that different loci might be involved.

Our data are the first to suggest that sporadic haemangioma is associated with somatic mutation events. These data showing $\mathrm{LOH}$ involving a subset of markers on $5 \mathrm{q}$, in association with the identification of a locus for hereditary haemangioma on $5 \mathrm{q},{ }^{5}$ are suggestive of a tumour suppressor gene for haemangiomas in this region.

There are many loci within the overlapping candidate regions, and several of these might have a role in the control of endothelial cell proliferation and differentiation. The vascular endothelial growth factor receptor 3 gene (FLT4) is mutated in hereditary lymphoedema, ${ }^{8}$ although haemangiomas are not reported as a feature in these affected families. The platelet derived growth factor receptor $\beta$ is expressed in vascular smooth muscle cells, and has a role in the recruitment of pericytes by developing blood vessels. ${ }^{9}$

The interferon regulatory factor 1 (IRF1) is a known tumour suppressor gene, which has been shown to be involved in gastric cancer and some forms of leukaemia. ${ }^{10}$ However, no specific role for IRF1 in the endothelial cell has been established. The SPARC (secreted protein acidic and rich in cysteine) gene encodes a protein that is secreted by endothelial cells, particularly after certain types of injury. ${ }^{11}$ SPARC also has a role in bone matrix formation. The fibroblast growth factor receptor 4 and the fibroblast growth factor 18 also map to the candidate region. All these genes have been sequenced in individuals from autosomal dominant haemangioma families, but no causative mutation has been identified in these genes (J Walter, personal communication, 2001).

The endothelial cell proliferation that gives rise to a haemangioma might be caused by the complete loss of a gene that acts as an endothelial growth suppressor. This situation would be similar to that seen in the "two hit" model for retinoblastoma. ${ }^{12}$ Under this model, the high frequency of sporadic haemangioma might be explained in two ways. Mutations in the haemangioma predisposing gene could be relatively common in the population, with the "second hit" occurring relatively infrequently. Alternatively, the region of chromosome $5 \mathrm{q}$ containing the haemangioma predisposing gene could be particularly prone to mutation in endothelial cells.

This tumour suppressor model for the formation of sporadic haemangiomas would be consistent with the clinical presentation. Most lesions arise in a single random location, although occasionally multiple lesions arise within a larger confluent area of skin. Disseminated haemangiomatosis can also occur. A single lesion might arise from a mutation in a single endothelial cell; multiple lesions would arise from a mutation in an endothelial precursor that multiplies to give multiple affected endothelial cells within one region, or occasionally throughout the body.

An alternative genetic model would be that the function of the gene mapping to the chromosome 5q locus might be particularly sensitive to gene dosage effects. In this case, either germline or somatic mutation leading to haploinsufficiency for the gene would be sufficient to predispose to haemangioma. Subsequent haemangioma formation would have to be initiated by a localised environmental insult, presumably arising in utero.

If loss of a tumour suppressor gene causes proliferation, this does not explain why haemangiomas usually undergo involution after proliferation. This could be explained if the proliferating cells subsequently differentiate, or are subject to a limitation in the number of cell divisions that they can undergo before apoptosis occurs. Even in the presence of a somatic mutation, haemangioma proliferation and involution will be influenced by growth factors in the microenvironment and changes in circulating hormones at the time of birth and during growth.

Our study provides further evidence that there is a genetic component to the aetiology of sporadic haemangiomas of childhood. Further studies are required to refine the candidate interval and identify the genes involved. 
We wish to thank Dr J Keeling (Royal Hospital for Sick Children, Edinburgh) for the haemangioma samples and review of the manuscript; Dr S Holloway (South-East Scotland Clinical Genetics Service) for assistance with the statistical analysis; Miss D Reinhardt for technical assistance; and Dr J Warner (Molecular Genetics Service, Edinburgh) for technical advice. This work was supported in part by AICR grant 99-154 American Heart Association Grant $9750153 \mathrm{~N}$, and a Wellcome biomedical collaborative grant. DAM is an established investigator of the American Heart Association.

1 Fishman SJ, Mulliken JB. Hemangiomas and vascular malancy and childhood. Pediatr Clin North Am 1993;40:1177-200

2 Kazue T, Mulliken JB, Kozakewich HPW, et al. Cellular markers that distinguish the phases of haemangioma during infancy and childhood. F Clin Invest 1994;93:2357-64.

3 Razon MJ, Kraling BM, Mulliken JB, et al. Increased apoptosis coincides with onset of involution in infantile haemangioma. Microcirculation 1998;5:189-95.

4 Blei F, Walter J, Orlow SJ, et al. Familial segregation of hemangiomas and vascular malformations as an autosomal dominant trait. Arch Dermatol 1998;134:718-22.

5 Walter JW, Blei F, Anderson JL, et al. Genetic mapping of a novel familial form of infantile hemangioma. Am 7 Hum Genet 1999;82:77-83.
6 Hahn M, Matzen SE, Serth J, et al. Semiautomated quantitative detection of loss of heterozygosity in the tumor suppressor gene p53. Biotechniques 1995;18:1040-7.

7 Magnusson PK, Wilander E, Gyllensten U, et al. Analysis of loss of heterozygosity in microdissected tumor cells from cervical carcinoma using fluorescent dUPT labelling of PCR products. Biotechniques 1996;21:844-7.

8 Karkkainen MJ, Ferrell RE, Lawrence EC, et al. Missense mutations interfere with VEGFR-3 signalling in primary lymphoedema. Nat Genet 2000;25:153-9.

9 Hellstrom M, Kaln M, Lindahl P, et al. Role of PDGF-B and PDGF-beta in recruitment of vascular smooth muscle cells and pericytes during embryonic blood vessel formation in the mouse. Development 1999;126:3047-55.

10 Nozawa $\mathrm{H}$, Oda E, Ueda $\mathrm{S}$, et al. Functionally inactivating point mutation in the tumor-suppressor IRF-1 gene identified in human gastric cancer. Int f Cancer 1998;77:5227 .

11 Goldblum SE, Ding X, Fu SE, et al. SPARC (secreted protein acidic and rich in cysteine) regulates endothelial cell shape and barrier function. Proc Natl Acad Sci US A 1994; 91:3448-52.

12 Cavenee WK, Dryja TP, Phillips RA, et al. Expression of recessive alleles by chromosomal mechanisms in retinoblastoma. Nature 1983;305:779-84.

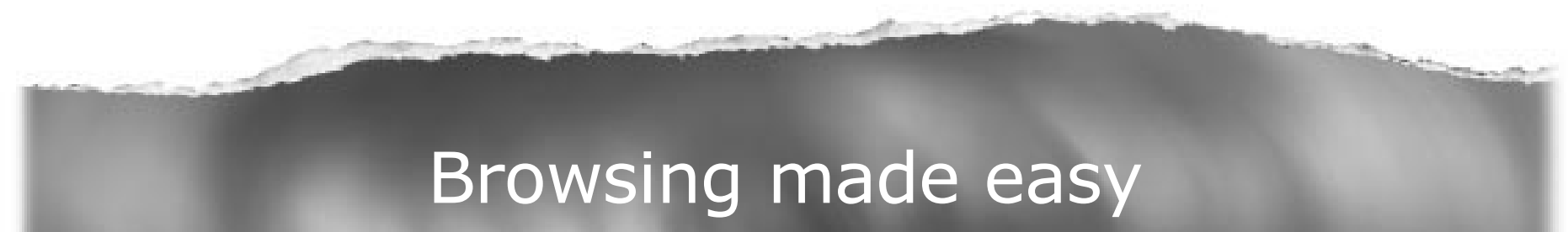

\section{Collections}

With a single click Collections allows you to find all articles that have been published in your chosen subject. Select from over 200 clinical and non-clinical topic collections and/or cross search other specialist journals, the BMJ and Cochrane Reviews

\section{wWw.jclinpath.com}

